\title{
Vagabunda y cautiva en París: paisaje urbano de la vulnerabilidad femenina en las novelas de entreguerras de Jean Rhys
}

\author{
Francisco José CORTÉs VIECO \\ Departamento de Filología Inglesa \\ Universidad Autónoma de Madrid \\ francisco.cortes@uam.es
}

Recibido: $08 / 09 / 2013$

Modificado: $02 / 11 / 2013$

Aceptado: 06/11/2013

\section{Resumen}

La escritora antillana Jean Rhys transforma en ficción su autobiografía para desgranar su dolorosa experiencia en el París de entreguerras, más protagonista narrativo que testigo escenográfico. Para ello, se infiltrará en la psique y los recorridos urbanos de sus dos heroínas en las novelas Quartet y Good Morning, Midnight. La ciudad será un ordenado territorio geométrico en manos patriarcales que la mujer intenta "feminizar" al escoger rutas erráticas y sinusoidales que enlazan sus calles con su mente, el pasado con el presente, el trauma con la evasión autodestructiva. Igualmente, los lugares públicos de la capital francesa invitan al desencuentro, y sus espacios privados son cárceles que escenifican la violencia de género y la conducta sadomasoquista con una víctima femenina.

Palabras clave: ciudad, mujer, marginalidad, victimización, encarcelamiento.

Title: A Wanderer and Captive in Paris: Urban Landscape of Female Vulnerability in Jean Rhys' Interwar Novels

\section{Abstract}

The city becomes a "leading character" in the narrative of Caribbean writer Jean Rhys, who fictionalizes her autobiography to explore her painful experience in Paris during the interwar period. She intrudes on the psyche and urban paths of her two heroines in the novels Quartet and Good Morning, Midnight. The French capital seems to be an ordered, geometric territory in patriarchal hands. In contrast, women try to "feminize" it by choosing erratic, oblique routes, which intertwine its streets and their minds, past and present, trauma and self-destructive evasion. Besides, the public places of this large metropolis contribute to thwarted meetings, and its private spaces turn into prisons, where the female characters become the victims of gender violence and sadomasochistic behavior.

Keywords: city, woman, marginalization, victimization, imprisonment. 
Para que cicatricen las heridas de la traumática Primera Guerra Mundial (1914-1918), el "alegre" París de los años veinte y treinta se maquilla para seguir siendo el orgulloso escaparate de la Belle Époque. Exhibirá al mundo el poder de la nación francesa y sus atributos: el capitalismo, el consumismo, los placeres hedonistas, la vida mundana e intelectual, el auge de la tecnología y de nuevas manifestaciones artísticas, como el cine y la fotografía. Mostrará su cosmética de bohemia y luminosidad al nativo y al turista: las exposiciones universales, los centros comerciales, las galerías de arte, los cabarets y el Moulin Rouge, los salones parisinos, los cafés, las tertulias literarias, la feria de las vanidades de la burguesía reinante y su armónica fisonomía arquitectónica, adoptada en el siglo XIX gracias a las reformas urbanísticas del Barón Hausmann. Según Eugenia Popeanga, la pérdida del Jardín del Edén obliga al hombre a erradicar elementos naturales del paisaje urbano y a construir modelos semejantes, o paraísos artificiales, que son los cimientos de una ciudad demoníaca, plagada de peligros y cloacas (Popeanga Chelaru 2009). Por debajo de su pulcro pavimento civil y su oferta de espectáculos y diversión, París cobija, e incluso ostenta con chovinismo, un oscuro subsuelo entre bambalinas de drogas, prostitución, alcohol, mendicidad y tragedia humana, que artistas y escritores locales y foráneos han sabido explotar con astucia para conversar en paradójica ósmosis con su perfil icónico de ciudad de ensueño y, simultáneamente, nutrir a sus obras de su carisma.

En calidad de melting pot cosmopolita y de cuna de la vanguardia en las artes, París atraerá antes del estallido de la Segunda Guerra Mundial en 1939 a sucesivas oleadas de expatriados anglonorteamericanos: intelectuales y literatos, tales como Ernest Hemingway, Ezra Pound, Ford Madox Ford, James Joyce o Henry Miller. Su aportación cultural con el jazz, el modernismo, los ecos de la lengua de Shakespeare y el desencanto con respecto a la civilización occidental contribuirán a consolidar la imagen de la capital gala como gran caleidoscopio de diversidad de cátedra y de multiculturalidad. La mujer anglosajona habitará esta urbe con desigual éxito: como vedette o espectro, rica o pobre. Josephine Baker, Isadora Duncan, Gertrude Stein o Anaïs Nin resplandecerán bajo los focos del triunfo profesional o el influjo de su mecenazgo artístico, mientras que su coetánea Ella Gwendolen Rees Williams (1890-1979), conocida bajo el pseudónimo de Jean Rhys, descenderá por el pasadizo de la memoria y la ficción autobiográfica hacia un demi-monde ${ }^{1}$ parisino de comercio con el cuerpo femenino, entre luces y sombras, entre opulencia y menesterosidad. Esta caverna

1 Término del escritor francés Alexandre Dumas (hijo) para referirse a un modus vivendi marcado por el hedonismo, el consumismo, los vicios sociales y una promiscuidad contraria a los valores burgueses imperantes. 
metropolitana estará poblada por una constelación de mujeres que giran alrededor de una órbita solar patriarcal, que son explotadas sexualmente por el hombre y estigmatizadas públicamente como concubinas, desheredadas y vagabundas. Rhys (des)dibujará a sus heroínas como daguerrotipos de sí mismas: desarraigadas geográfica y emocionalmente, a la deriva y sin rumbo fijo; despojadas de familia, educación y ocupación estable; asustadas, insolventes e indefensas en ciudades europeas. Se internarán en un círculo vicioso al comprar la seguridad brindada por el hombre a cambio de su servilismo, y esta dependencia económica llevará a otra psicológica y a la pérdida de confianza en sí mismas, que vetará su autonomía y reforzará su sujeción al poder del dinero (Abel 1979: 170). Serán muñecas infantilizadas, erotizadas y adoradas por sus dueños en un primer tiempo. Pero cuando ya estén desgastadas, rotas o alcoholizadas, serán abandonadas y encerradas en infectos hoteles.

Con ímpetu confesional, Jean Rhys complicará la tradicional usurpación de la identidad de la mujer, clasificada como la "Otra", por el poderoso "Yo" masculino del patriarcado reinante, cuando escoge intercalar en su narrativa la violencia sexual con la opresión ideológica ejercida por el Imperio Británico sobre la colonizada y la inmigrante. De padre galés y madre criolla, nació en la isla caribeña de Dominica. La cruel historia de esta posesión de ultramar forjará su propia cosmogonía binaria: blanco/negro, amo/esclavo, virgen/prostituta, niña buena/niña mala (Moran 2007: 110). Pero no sólo las tensiones raciales y de género derivadas de la conflictiva interacción entre la madre patria y el nativo invadido, 0 el empobrecido colono europeo tras la abolición de la esclavitud, prevalecen en su laureada novela Wide Sargasso Sea (1966), ubicada en las Antillas Occidentales y que inaugura la literatura poscolonial. La sensación interiorizada -como mujer y extranjera- de discriminación, incomprensión y desprecio trasatlántico será igualmente un corrosivo sustrato narrativo que intoxicará su poco conocido corpus literario de entreguerras en el marco de dos metrópolis: Londres y París.

Tras desembarcar en la capital inglesa con 16 años, Jean Rhys realizará su tournée iniciática por Europa como corista y maniquí, concubina y demi-mondaine. Sufrirá amores tormentosos, matrimonios fracasados, la precariedad económica, la dependencia financiera y emocional del hombre, el ostracismo como escritora, la autodestrucción del alcohol, un aborto y la defunción de un bebé recién nacido. Su azarosa vida será el germen de su creación artística, hasta el punto que A. C. Morrell criticará que "relate la misma historia 46 veces" (1979: 243). En sus diarios, recordará el abuso sexual y psíquico de Mr. Howard -un terrateniente inglés, casado y de avanzada edad-, con quien mantuvo una relación sadomasoquista durante su adolescencia en Dominica (Savory 2009: 
4). Su estética narrativa de la tortura sexual, perpetrada por villanos contra sus débiles víctimas femeninas, reproducirá esta violación del "invasor masculino y colonialista" contra una niña vulnerable y desvalida que asimilará toda la culpa y se odiará a sí misma. Quartet (1929), Voyage in the Dark (1934) y Good Morning, Midgnight (1939) serán piezas contiguas que recompondrán la anatomía emocional y corporal de una única mujer -ella misma- durante diversos episodios de su experiencia adulta por el viejo continente, mientras que Wide Sargasso Sea regresará a su niñez y reescribirá un mito caribeño distorsionado por el canon literario: la "loca del ático" de la novela victoriana Jane Eyre (1847) de Charlotte Brontë. Todas ellas conforman la tipología de la mujer maltratada. Los síntomas de este abuso de género -físico, sexual y psicológico- indican, hoy en día, que el hombre ejerce autoridad y control sobre ella, coaccionándola para imponer su voluntad en detrimento de sus derechos $y$ emociones (Walker 1984: 42). Además de ser vejadas por maridos o amantes, los personajes femeninos de Jean Rhys también se autolesionan corporal y mentalmente. Kate Millett sostiene que, para la teoría freudiana, el masoquismo es femenino y la feminidad es masoquista; y denuncia que sus postulados justifiquen que, genéticamente y más allá de imposiciones sociales, la mujer sea un objeto sexual y pasivo que es proclive al sufrimiento (Millet 1969: 194). Aunque sea tachada de antifeminista al consentir aparentemente este sometimiento ideológico sin promover su emancipación, la autora preferirá tantear, sin enjuiciar, la antirromántica realidad parasitaria de tristes "chicas de alegre vida" que eligen o se resignan a la erótica del dolor. Si espacialmente las nociones de hogar y exilio son intercambiables, temporalmente no podrán huir de su pasado y serán humilladas por el hombre en presente continuo que no vaticinará un futuro regenerativo. De hecho, sus novelas se centrarán en obsesiones femeninas y narrarán una doble historia: eventos contemporáneos que reactivarán experiencias pretéritas, que emergerán de forma fragmentada y transcribirán literariamente experiencias lacerantes (Moran 2007: 118). Al acuñar la "escritoterapia", Suzette Henke señala el potencial curativo que tiene para la mujer transcribir su propia vida (2000: xv). Esta escritora canalizará episodios traumáticos de victimización en primera persona dentro del espacio cívico gracias a la "máscara de la ficción" que cicatrizará sus heridas con un balsámico ejercicio pseudopsicoanalítico.

Jean Rhys, caribeña y cosmopolita, se encuadraría formalmente a caballo entre la autobiografía y la ficción, la literatura colonial y la postcolonial, las vanguardias y la posmodernidad, tradiciones europeas y el espíritu pionero americano. Su escritura urbana desafinará respecto a la fiesta y las bacanales de las experiencias de sus compatriotas anglosajones Ernest Hemingway y Henry Miller en la 
capital gala. De hecho, armonizará más con el naturalismo de Zola o los cuadros parisinos de Baudelaire, caracterizados por suciedad, mendicidad, podredumbre y drama humano. Bajo el encantamiento modernista, Rhys explorará la psique femenina en un tiempo fluido que, sin pronóstico de futuro feliz, amalgama el presente y el pasado, en un espacio geográfico muy perfilado: la ciudad como inmutable protagonista y testigo excepcional. Dos de las novelas mencionadas, Quartet y Good Morning, Midnight, se localizarán en un París de entreguerras que aprisiona y libera a sus heroínas durante su periplo errante y psíquico por sus amplias avenidas y guaridas carcelarias. En este artículo, exploraré la cartografía urbana como universo mental y geográfico de estas mujeres, delimitada por cuatro puntos cardinales de vulnerabilidad femenina: la cosificación erótica, la violencia de género, el aislamiento introspectivo y el masoquismo autodestructivo del alcohol. Si bien las protagonistas de estas obras sucumben a su drogodependencia de hombres sádicos bajo el marco de habitaciones en infectos cuartos parisinos que las aprisionan y ahogan, la capital francesa será igualmente la aliada en sus técnicas de "guerrilla": andar y deambular sin rumbo por sus calles para transformar el espacio urbano en territorio femenino. Su fijación serán los barrios de Montparnasse y Quartier Latin, dotados de rasgos antropomórficos y una fisonomía distintiva: "When you go from one part of Paris to another, it's just like going from one town to another -even from one country to another" (Rhys 1939: 65). Sus calles, plazas y jardines serán un conglomerado homogéneo que no permite su individualización, aunque conformen el mapa de un reconocible París al nombrar lugares no ficticios: St. Michel, rue de Rennes, rue Vavin, rue Vaugirard, e incluso locales que aún existen hoy en día: Café du Dôme, la Rotonde, la Coupole o Deux Magots. Las nuevas tecnologías: cines en Champs Elysées, exposiciones de Trocadéro y el transporte en metro no serán protagonistas, pero sus apariciones ocasionales reflejan el cambio morfológico de la ciudad moderna. Coetáneo de Jean Rhys, Le Corbusier observa que el hombre camina en línea recta porque sabe hacia dónde se dirige (1929: 5). Regido por la razón y la lógica, trazados lineales y ángulos rectos dictan sus acciones que tienen un objetivo definido y se dirigen hacia una meta clara (Le Corbusier 1929: 17). En virtud de esta misma teoría antropológica, el arquitecto francés sostiene que París respeta el orden y las proporciones gracias a una organización y estructura urbanas gobernadas por principios geométricos que le aportan belleza, equilibrio y permanencia a lo largo y ancho de su historia (Le Corbusier 1929: 25). En contraposición, esta escritora antillana romperá la simetría y regularidad de fórmulas matemáticas pertenecientes a un territorio municipal erigido en base a normativas patriarcales. El plan urbanístico de las dos heroínas estudiadas desconstruirá la ciudad masculina como dominio de experiencias 
dolorosas y placenteras: una joven Marya construye un París sinusoidal en presente continuo, mientras que una Sasha madura reconstruye un tiempo pretérito desde los escombros de su actual vida derruida, cuando viaja para revisitar la ciudad de sus recuerdos, donde fue feliz y desgraciada.

La novela Quartet insinuaría un capítulo autobiográfico de Jean Rhys $^{2}$. Está ambientada en un París aparentemente bohemio y burbujeante con elegantes cafés y célebres clubs nocturnos, pero también tortuoso y laberíntico, plagado de recovecos lúgubres y celulares. Su narrativa en tercera persona y la escenografía cinematográfica de la urbe francesa, desde Montmartre hasta Montparnasse, estarán habitadas por expatriados como la británica Marya y su esposo polaco Stephan, o por un sofisticado matrimonio inglés con buena posición socioeconómica: Hugh y Lois Heidler, que conforman el "cuarteto" de la autora. Sola en Francia, la heroína de esta obra lleva una vida ociosa, aunque nunca desahogada, en la capital gala, donde "mata" el tiempo en sus calles y lugares públicos, mientras que su marido es un marchante de arte que se verá involucrado en negocios fraudulentos. Su unión conyugal no sólo estará definida por la despreocupación y la precipitación, sino también por el respeto de unas reglas de juego amoroso preestablecidas de antemano: la superioridad intelectual de Stephan y la docilidad de su mujer, que no actúa ni decide por sí misma. Ya antes de contraer matrimonio demostrará su seguridad en sí mismo para garantizar la felicidad de Marya: "I know all about you. I know you far better than you know yourself. I know why you aren't happy. I can make you happy" (Rhys 1929: 17). Ella penetrará en el amenazador territorio de la fantasía romántica, externa al orden social, donde estar enamorada implica ser poseída física y espiritualmente, por lo que vivirá en un estado más allá de la volición y una identidad propia (Howells 1991: 48). Aunque su marido le reproche su comportamiento errante, la heroína preservará su libertad de pensamiento para trazar rutas transversales y escapar del trazado urbanístico lineal del Paris haussmanniano. Deambulará por un territorio subjetivo, sin punto de origen ni de destino, que transforma un espacio público en otro personal e internalizado:

Montparnasse was full of these streets and they were often inorderly long. You could walk for hours. The rue Vaugirard, for instance. Marya had never yet managed to reach the end of the rue Vaugirard, which was a very respectable throughfare on the whole. (Rhys 1929: 8)

${ }^{2}$ Basada en la relación extramatrimonial de Rhys con su mecenas: el escritor Ford Madox Ford, que vivía en París con la pintora Stella Bowen, mientras que su marido fue arrestado por transacciones financieras ilegales. 
La práctica de andar sin mapa ni meta gestará un París femenino a su conveniencia. El medio urbano se muestra descomunal e inabarcable y, por tanto, escapa en teoría del control masculino. En él, los transeúntes la confunden con una prostituta o una vagabunda, quizás por sus recorridos erráticos y pausados. Aunque la ciudad evidencie su desarraigo y marginalidad, no está acotada ni es un lugar opresivo porque le permite escoger alternativas vías de ensoñación fantástica a lo largo de bulevares a media luz, frente al bullicio de otras arterias. Estos trayectos intuitivos por el pavimento cívico favorecerán su evasión de una vida vacua que no cumple con las expectativas adoctrinadas por su marido cuando decidieron buscar fortuna en la capital gala:

She vaguely disliked the Boulevard St. Michel with its rows of glaring cafés, and always felt relieved when she turned into the Boulevard Montparnasse, softer, more dimly lit, more kindly. There she could plunge herself into a dream. (Rhys 1929: 67)

A menudo, Jean Rhys dibuja París como ciudad viva y dinámica desde la mirada de la "Otra", la mujer extranjera y excluida, quien pierde corporeidad frente a la presencia estelar y el ritmo frenético de la corpulenta metrópoli:

The Place Blanche, sometimes so innocently sleepy on an afternoon, was getting ready for the night's work. People hurried along cowering beneath their umbrellas, and the pavements were slippery and glistening, with pools of water here and there, sad little mirrors which the reflections of the lights tinted with a dull point of red. The trees along the Boulevard Clichy stretched ridiculously frail and naked arms to a sky without stars. (Rhys 1929: 26)

Este decorativo mobiliario vegetal, aislado dentro del entramado urbano, encarna la propia fragilidad de la heroína. De hecho, el espacio tiene un dueño masculino, por lo que su potencial liberador y sin fronteras como reino femenino, se atenúa. Su esposo será encarcelado después de ser descubierto por la policía vendiendo obras de arte robadas. En la figura de Stephan, Jean Rhys sugiere, aunque no desarrolla, una famosa faceta de la capital francesa como ciudad de las antigüedades: los negocios se cierran en cafés parisinos, que no son propicios a la intimidad y sí a la traición cuando son ilícitos. Marya caerá presa de las garras de Mr. Heidler por culpa de su falta de recursos económicos y protección masculina, que configurarán sus coordenadas de dependencia y desamparo. Antes de conocer el delito imputado a este marchante de arte, será paradójicamente increpada a la orilla del Sena por un transeúnte: "Hé, little one. Is it for tonight the suicide?" (Rhys 1929: 29), 
mientras que contempla, con nocturnidad y ensimismamiento, las aguas de la arteria parisina, vinculada tradicionalmente al ahogamiento y a los cadáveres, eminentemente femeninos, encontrados en esta vía fluvial.

Hugh y Lois insistirán en ofrecer cobijo, manutención y mecenazgo a una compatriota en apuros, regidos por un afán filantrópico y sin, al parecer, exigir contraprestación alguna. Encarnan a un París masculino, ordenado, sin rutas nómadas, y claramente definido por los cafés y restaurantes que frecuentan (Zeikowitz 2005: 8 ). No es casual que habiten en el ático de un edificio de gran altura en la Avenue de l'Observatoire, como "torre de vigilancia" comparable al modelo penitenciario "panóptico" desde el cual divisan y controlan el conjunto de la ciudad gracias a este privilegiado enclave panorámico. A pesar de su reticencia inicial, Marya no tendrá escapatoria. Terminará viviendo allí. Pronto se sentirá prisionera y observada, mientras que Hugh utilizará su allure paternalista, su astucia depredadora y la desinhibición del alcohol para que la heroína claudique en sus objeciones al adulterio durante una noche en la que, deliberadamente, su esposa les deja a solas. De este modo, París será un espacio de duplicidad clandestina y transgresión sexual. Heidler establecerá las cláusulas de desigualdad de su affaire extramatrimonial, psíquicamente sadomasoquista, en el que él ejerce el poder económico y la autoridad para atrapar, poseer y desechar a la mujer entendida como genérico objeto sexual:

I knew that I could have you by putting my hand out [...] I've been watching you; I watched you tonight and now I know that somebody else will get you if I don't. You're that sort [...] I've every right to take advantage of it if I want to. (Rhys 1929: 72)

Aunque esté casada, la califica explícitamente como "chica fácil" a la entera disposición del mejor postor. Perdonando el insulto, la respuesta corporal de Marya será someterse a la subordinación emocional y sexual ordenada por su nuevo amo: "When he touched her she felt warm and secure, then weak and so desolate that tears came into her eyes" (Rhys 1929: 72-73).

En el marco de relaciones emocionales con maltrato masculino, Judith Herman establece que el deseo desesperado de la mujer por recibir atenciones y cuidados de su pareja impide que se perciba el peligro de no establecer fronteras seguras y saludables entre ambos. Perderá la objetividad al denigrarse a sí misma, idealizar al hombre e, inconscientemente, obedecer sus órdenes, llegando a provocar situaciones amenazantes que predisponen al abuso de género (Herman 1992: 111). De igual modo, la heroína se transfigura en tabula rasa, servil y dócil, que cometió el error de confesar su vulnerabilidad a Mr. Heidler: "I don't want to be hurt any more... If I 
am hurt again I shall go mad" (Rhys 1929: 77), quien aprovechará esta debilidad en su propio beneficio. Arrastrada por esta infatuación amorosa de atracción más mental que corporal, su credulidad respecto a la personalidad y conducta de su dueño responden a la imperiosa necesidad de ser socorrida económica y sentimentalmente. Este expatriado de mediana edad y escaso atractivo erótico no persigue satisfacer su libido ni alardear de su potencia sexual en su harem parisino, sino que desea dominar psicológicamente a una chica frágil debido a su impotencia o su ineptitud amatoria: "He wasn't a good lover [...] He didn't really like women. She had known that as soon as he touched her. His hands were inexpert, clumsy at caresses; his mouth was hard when he kissed" (Rhys 1929: 118). En contraposición, Marya articulará un preestablecido guion masoquista y sin enmienda posible que oscila entre la abnegación a su amo y el ataque feroz (Howells 1991: 30). Unas veces, rinde pleitesía a Heidler: "I'll do anything to please you" (Rhys 1929: 96), pero otras, estalla al no soportar este triángulo amoroso: "D'you think I am a bonne or something to be made love to every time the mistress's back is turned?... You must be the cruellest devil in the world" (Rhys 1929: 100). Sin embargo, la obediencia de Marya se torna en rebelión subrepticia cuando ésta prefiere la libertad de calles solitarias y oscuras, donde dialoga en silencio con gatos -otras criaturas mendigantes, aunque autónomas, a diferencia de ella: "It was a beautiful street. The street of homeless cats, she often thought. She never came into it without seeing several of them, prowling, thin vagabonds, furtive, aloof, but strangely proud. Sympathetic creatures, after all" (Rhys 1929: 65), en vez de disfrutar de las luces de neón de la atractiva urbe o de la compañía de los Heidler.

Mientras que el círculo de amistades de sus mecenas desprecia a Marya, Lois guarda las apariencias en público y autoriza el desliz sexual de su marido. Adopta la estrategia de la esposa que no tolera escenas melodramáticas y opta por la proximidad de su rival para asegurarse de que se trata de una aventura pasajera que no pondrá en riesgo su bienestar socioeconómico. De hecho, París será también una cárcel para esta pareja inglesa, presa de su matrimonio y condenada a perpetuar roles sociales de hipocresía y decoro de cara a la galería (Zeikowitz 2005: 12). La esposa oficial actuará con la heroína como si ésta fuera una niña a la que llevar a un parque de atracciones para que se monte en un carrusel, en consonancia con la infantilización de su amante ejercida por parte de Heidler. Si bien a la joven le aflige el dolor ocasionado a su benefactora, este ménage à trois emocional será insostenible a medio plazo. Extenuado por las crisis de histeria de Marya, Heidler la traslada del hogar conyugal a 
un hotel parisino ${ }^{3}$. En su afán por imponer analogías coherentes, este hombre acude a un alojamiento destinado a prostitutas y concubinas para que la heroína se transfigure en una de ellas al integrar, en su cuerpo y mente, los atributos conferidos por el hombre a este espacio urbano. Su localización próxima a la estación de ferrocarril de Montparnasse, lugar de tránsito, acrecienta su cualidad de enclave íntimo de tráfico y trasiego de gente y de mercancías. Marya se rebelará al increpar a su amante y rechazar la denigración ligada a sus cuartos sofocantes y sórdidos: "Don't you understand that I hate this louche hotel and the bedroom and the wallpaper and the whole situation, and my whole life?" (Rhys 1929: 129).

Si bien antes encarnaba simbólicamente a una mascota doméstica o una niña adorable que divertía a su "dueño/padre" en el hogar, la protagonista de Quartet es ahora una "jovencita" castigada por su mal comportamiento y una bestia salvaje apresada, no en una jaula de oro, sino en un pequeño, oscuro y asfixiante cuarto del inframundo parisino: "Fright of a child shut up in a dark room. Fright of an animal caught in a trap" (Rhys 1929: 90). Durante su encarcelamiento, su rabia originará elucubraciones mentales que escenificarán impulsos homicidas contra Lois, y reactivará la dinámica de dependencia emocional al arrojarse a estados de perpetua incertidumbre y de espera, a merced del hombre que la mantiene $y$ decide unilateralmente la periodicidad de sus encuentros amorosos. Resignada al estatus de cautiva, se obsesionará con su captor. Le recriminará su conducta evasiva y que priorice su matrimonio. Durante largas horas de soledad y aislamiento en este siniestro habitáculo de un París cómplice, emociones contradictorias golpean constantemente su cerebro: "I love him. I want him. I hate him. And he's a swine. He's out to hurt me. What shall I do? I love him. I want him. I hate him" (Rhys 1929: 124). Su cuadro clínico de severa psicopatía dará lugar a ciclos de ansiedad y pánico debido a la posible pérdida del ser amado, que se traducen en metáforas de amenaza corporal y autoflagelación:

If this was love -this perpetual aching longing, this wound that bled persistently and very slowly. And the devouring hope. And the fear. That was the worst. The fear she lived with -that the little she had would be taken from her. Love was a terrible thing. You poisoned it and stabbed at it and knocked it down in the mud -well down- and it got up and staggered on, bleeding and muddy. (Rhys 1929: 122)

Jean Rhys seguirá apelando a una iconografía de desvalidos animales de compañía para corroborar su coreografía narrativa de

\footnotetext{
${ }^{3}$ No resulta casual que este alojamiento se llame Hôtel du Bosphore, emulando los harenes otomanos.
} 
humillación física y degradación espiritual de la heroína ante su dueño-torturador al mendigarle que sea clemente con sus sentimientos: "'Oh, please be nice to me. Oh, please say something nice to me. I love you'. She was quivering and abject in his arms, like some unfortunate dog abasing itself before its master" (Rhys 1929: 131). Como respuesta a su ascendente displicencia, la hiperestesia de Marya se agudiza y origina incontrolables deseos de dormir/morir, y alucinaciones debido al excesivo consumo de somníferos y alcohol. Mientras que su adicción al licor somatiza su subordinación al hombre, la de su amante, según Jane Nardin, refleja la excusa masculina para eludir la responsabilidad de sus actos y camuflar su perversión (Nardin 2006: 53). La ciudad "prosigue en trayectoria recta" conforme al trascurso de las estaciones: "The spring came early that year and very suddenly. So that one day the branches of the trees in the Luxembourg Gardens were bare and grim and the next they waved cool leaves in a kind wind" (Rhys 1929: 67). En cambio, Marya sufrirá un retroceso psíquico que debilitará aún más su organismo. Asociando Montparnasse con sus carceleros, los Heidler, se evadirá al recordar con nostalgia su vida anterior con Stephan en Montmartre:

She remembered the dingy streets, the vegetable shops kept by sleek-haired women, the bars haunted by gaily dressed little prostitutes who seemed to be perpetually making the gesture of opening their bags to powder their noses. Over the whole of the quarter the sinister and rakish atmosphere of the Faubourg Montmartre spread like some perfume. (Rhys 1929: 166-167)

Comprenderá que en esta época todavía tenía ilusiones y disfrutaba con pequeños detalles cotidianos y urbanos que le invitaban a percibir que París era un espacio de oportunidades. La fantasía pornográfica de sometimiento femenino de Hugh le importunará. Hastiado de las exigencias afectivas de su concubina, no vacilará en ultrajarla verbalmente y desembarazarse de ella enviándola al "exilio" en la Riviera francesa, donde su paroxismo emocional persistirá y será sintomático de que su malestar no es achacable a la metrópoli. Mientras tanto, Stephan cumple su condena en prisión y reclama la presencia de la heroína en la capital. En un primer encuentro, admite su desencanto con una ciudad que no es la meca prometida que él esperaba: "Paris is as rotten as anywhere else and worse" (Rhys 1929: 169). En otro, Marya le confiesa que la penuria económica desencadenó su adulterio. Como corolario de su estado patógeno de confusión emocional propio de su condición de víctima, afirmará desear huir con su marido a otro país y haber permanecido junto a su amante sólo movida por fines lucrativos. Pero, fruto de un lapsus mental, de un irrefrenable amago de 
sinceridad o de un gregarismo adoctrinado por su "amo", revelará simultáneamente seguir enamorada de su benefactor, no de su cónyuge. Absorto en la traición conyugal y en su drama personal como expresidiario, la reacción de Stephan será brutal al agredirla con violencia. Aunque amenace con asesinar a su enemigo, escapará de Francia con otra mujer. Rhys coronará el desenlace de Quartet con la imagen de una mujer vejada y golpeada que es abandonada por los dos hombres de su vida, y que se halla inconsciente, tendida en el suelo de un hotel barato de París. Así, dramatizará las secuelas corporales y mentales de una experiencia masoquista que podría degenerar en reincidencia: abierta su celda, la mujer maltratada opta por seguir enjaulada en vez de volar en libertad, y por deleitarse en la erótica del modus vivendi en cautividad con uno de sus antiguos dueños o con el próximo. De hecho, su dependencia ambiental del espacio carcelario de la ciudad es más narcótica que el terror ante la consumación de la deserción masculina.

Prosiguiendo su andadura literaria, Rhys exhumará el sustrato narrativo de Marya -sexualizada, denigrada y maltratada- durante los años veinte para proyectar en la siguiente década su consanguineidad con Sasha Jansen, protagonista de Good Morning, Midnight, una inglesa madura que deambulará, no por un París monumental de bellas postales, sino por otro poco turístico e infrahumano, aunque reconocible por su peculiaridad urbana y que, igualmente, es el escenario de canciones de desamor e indigencia de Edith Piaf en Pigalle. Despojada de un argumento perfilado y de cruciales sucesos externos, esta novela se infiltra en la subjetividad de una voz femenina que, en primera persona, segrega pensamientos, recuerdos y emociones deshilvanadas, aleatorias y traumáticas. La ciudad no será el espacio de acciones trepidantes ni de actividades placenteras, sino de procesos cognitivos, del aislamiento y el sufrimiento humano. Sasha también será una vagabunda errante en un París laberíntico, que dibuja una ruta tortuosa y sinuosa por los recovecos de su psique. Las técnicas modernistas del fluir de la conciencia y el monólogo interior permiten a su creadora fracturar el orden cronológico y la delineación urbana para introducirse en un eje espacio-temporal psíquico -caótico, disperso y femenino-, que engarza un presente vacante con un pasado poblado, aunque siempre respete una única constante en su narrativa: la localización metropolitana. El deseo masoquista de ciudad de esta heroína la lleva a revisitar la capital francesa y vagar por unos escenarios conocidos donde fue feliz con su esposo Enno hace tiempo, pero donde fue igualmente desgraciada tras la deserción de éste y la defunción de su bebé recién nacido. Gracias a una exigua renta que percibe cada mes, subsiste en cuartos-zulo de insalubres hoteles de Montparnasse, ubicados en el mismo impasse de su propia existencia. No obstante, estos escondites carcelarios 
serán un acogedor refugio frente a los depredadores que pueblan las calles parisinas: "A room is a place where you hide from the wolves outside" (Rhys 1939: 38). La novelista emplea metáforas de ahogamiento y rescate que sugieren tendencias autodestructivas de esta mujer apátrida: "Saved, rescued, fished-up, half-drowned, out of the deep, dark river, dry clothes, hair shampooed and set. Nobody would know I had ever been in it. Except, of course, that there always remains something" (Rhys 1939: 10), que son articuladas de forma elíptica para garantizar que sólo ella, como víctima, conoce su naturaleza. A pesar del riesgo de una potencial recaída autodestructiva con su retorno a París, no desea recordar ni redactar este drama íntimo para satisfacer la curiosidad del lector: "Now I have forgotten [...] the drowning [...] You jump in with no willing and eager friends around, and when you sink you sink to the accompaniment of load laughter" (Rhys 1939: 10), pero sí subraya la culpabilidad del género humano en su propio descarrilamiento.

Jean Rhys insiste en que París no es la ciudad del amor romántico, más bien pone de relieve su insolidaridad, mezquindad y frialdad en el umbral del inminente conflicto bélico a finales de los años treinta. La urbe será un espacio de descortesía y agravio por los insultos que Sasha recibe como "vieja inglesa borracha". La autora muestra la hostilidad de la población autóctona con respecto a extranjeros de todas las nacionalidades: rusos, árabes o latinos. La comunidad de, supuestamente, acaudalados anglosajones como ella, será también el blanco de desprecio de comerciantes movidos por el odio xenófobo, más que por intereses económicos: "I go into a tabac. The woman at the bar gives me one of those looks: what do you want here, you? We don't cater for tourists here, not our clientele" (Rhys 1939: 104). De hecho, la novela excluye cualquier interacción positiva con los franceses y su idioma. En sus recorridos urbanos como vagabunda, sólo goza de la compañía de la ciudad, y resalta que su pobreza es la causa que justifica que las puertas de los hogares permanezcan cerradas ante su paso:

Walking in the night with the dark houses over you, like monsters. If you have money and friends, houses are just houses with steps and a front-door -friendly houses where the door opens and somebody meets you, smiling. If you are quite secure and your roots are well struck in, they know. They stand back respectfully, waiting for the poor devil without any friends and without any money. Then they step forward, the waiting houses, to frown and crush. No hospitable doors, no lit windows, just frowning and darkness. Frowning and leering and sneering, the houses, one after another. (Rhys 1939: 32)

Sasha percibirá malévolas voces no identificadas de su pasado parisino -reales, imaginarias o fruto de brotes paranoicos- que le 
exhortan a elegir una muerte acuática ${ }^{4}$ en la ciudad: "Why didn't you drown yourself in the Seine?" (Rhys 1939: 42). Sin vislumbrarse "puentes humanos" de solidaridad, sus aguas fluviales que dividen la ciudad en dos mitades: Rive Gauche y Rive Droite, igualmente fracturan los dominios terrestres entre la vida y el más allá. No serán, por lo tanto, el medio líquido de purificadoras abluciones, sino el abrazo mortífero y feminicida hacia un desplome putrefacto y ahogador. En reiterados episodios de precariedad económica, la heroína también barajará el suicidio en dos ocasiones mediante el abuso del alcohol y compuestos químicos después de días de ayuno: "I made up my mind to kill myself -the usual whiff of chloroform. Next week, or next month, or next year I'll kill myself. But I might as well last out my month's rent, which has been paid up, and my credit for breakfasts in the morning" (Rhys 1939: 86), que será abortado y/o diferido, por temor o puro pragmatismo, a un futuro sin fecha concreta. Sasha admitirá que su adicción a la bebida incide en su deterioro cognitivo, y que la conduce a un estado terminal en el que esta sustancia se transforma en el ansiolítico clave al que recurre para sustentar su proyecto en presente continuo de acabar gradualmente con su vida:

It was then that I had the bright idea of drinking myself to death [...] Now whisky, rum, gin, sherry, vermouth, wine with the bottles labelled 'Dum, vivimus, vivamus...' Drink, drink, drink... As soon as I sober up I start again. I have to force it down sometimes. You'd think I'd get delirium tremens. (Rhys 1939: 43)

Su toxicomanía corroboraría la teoría de Al Alvarez de que la dependencia del alcohol y las drogas es un "suicidio crónico". Esta tipología es propia de quien se mata lentamente con el pretexto de no soportar una vida intolerable, a la vez que niega su intención autodestructiva y se avergüenza tras los efectos analgésicos de las sustancias ingeridas (Alvarez 1971: 155). Cuando está ebria, funde espacios privados y públicos de París pertenecientes a su presente y pasado, que pasan por su mente como instantáneas fotográficas:

This damned room- it's saturated with the past... It's all the rooms I've ever slept in, all the streets I've ever walked in. Now the whole thing moves in an ordered, undulating procession past my eyes. Rooms, streets, streets, rooms... (Rhys 1939: 109)

\footnotetext{
${ }^{4}$ Esta alusión a la muerte acuática está ligada al culto de "L'Inconnue de la Seine": la máscara mortuoria del cadáver de una joven no identificada que decidió acabar con su vida en la arteria fluvial de París, y que prevaleció en las artes europeas del siglo XX como mito de un suicidio femenino bello y sereno.
} 
Esta degradación física y mental de Sasha, con periódicas incursiones suicidas, estará igualmente motivada por sus dificultades para asumir con resignación su envejecimiento biológico. El título de la novela, Good Morning, Midnight, ya alude a su reticente saludo de bienvenida a una nueva edad con los 40 años, metaforizado por el ocaso de la medianoche. El autosuministro consumista de rituales de belleza -la cosmética, perfumes, teñirse el pelo, la moda y complementos- que París ofrece a las mujeres será el antídoto o el consuelo de la heroína:

Tomorrow I'll go to the Galeries Lafayette, choose a dress, go along to the Printemps, buy gloves, buy scent, buy lipstick, buy things costing fcs. 6.25 and fcs. 19.50, buy anything cheap. Just the sensation of spending, that's the point [...] And when I have had a couple of drinks I shan't know whether it's yesterday, today or tomorrow. (Rhys 1939: 145)

Pero su fugaz efecto placebo no conseguirá mitigar la tortura psicológica derivada de los estragos causados por el irreversible paso del tiempo en su cuerpo: semblante demacrado, arrugas, flacidez, manchas, deformación e hinchazón. Popeanga (2009) sostiene que las grandes superficies comerciales son un paraíso de las damas de tipo artificial al aunar en un mismo espacio cielo e infierno. En un episodio retrospectivo de Good Morning, Midnight, Rhys evoca estos espacios parisinos de aparente glamour desde la perspectiva de Sasha, una empleada maltratada y explotada por empresarios franceses en la Avenue Marigny, aunque también ignorada por los acaudalados compradores ingleses, o por compatriotas que visitan París cuando trabaja de guía turística en Place de I'Opéra. Su precariedad profesional y la displicencia hacia el subalterno serán los efectos colaterales de la deshumanización de la sociedad capitalista y consumista que sufrirá en primera persona. De regreso a su presente, su condición de mujer madura, solitaria y depresiva, hundida ya en la ruina económica y moral, provocará reacciones dispares entre el público parisino que ella se cruzará en su periplo callejero. Por un lado, desprecio e indiferencia, que despertarán sus instintos homicidas: "When you're not expecting it, I'll take a hammer from the folds of my dark cloak and crack your little skull like an eggshell [...] One day, one day... Now, now, gently, quietly, quietly..." (Rhys 1939: 52). Por otro, compasión por parte de camareras de los cafés que frecuenta y que hará peligrar aún más su instinto de conservación: "Now I am going to cry... If I do that I shall really have to walk under a bus when I get outside" (Rhys 1939: 51). Paradójicamente, los clubs nocturnos y cafés parisinos no serán lugares de encuentro y diversión, sino de soledad y apatía para Sasha. Intenta ser sólo testigo y otorgar el protagonismo a París, 
pero distinguirá espacios públicos y privados que son inofensivos o acogedores de otros inhóspitos:

My life, which seems so simple and monotonous, is really a complicated affair of cafés where they like me and cafés where they don't, streets that are friendly, streets that aren't, rooms where I might be happy, rooms where I shall never be, looking-glasses I look nice in, looking-glasses I don't, dresses that will be lucky, dresses that won't. (Rhys 1939: 46)

Para protegerse de las agresiones externas de transeúntes franceses -hostiles o clementes- se aferrará nuevamente al alcohol de forma escapista. Este mecanismo de autodefensa contra el dolor emocional agrava su patología psiquiátrica y la arrastra hacia una existencia robótica y nómada por una urbe -su única amiga que la conoce: "Nobody else knows me, but the street knows me" (Rhys 1939: 107). Sus interacciones con otros extranjeros, tan desarraigados como ella, no atarán lazos fraternales entre ellos debido a la aguda introspección de Sasha en su propia miseria. Sin embargo, estas relaciones delatan un clima parisino de amargura generalizada y comunicación ineficaz. Rhys inundará su prosa con flashbacks del pasado de su heroína que evidencian una memoria errática, aunque sí fotográfica. Sin embellecimiento del impresionismo pictórico de épocas pretéritas, recapitulará episodios traumáticos que vivió París, ya que su acumulación exponencial justifica su deterioro psicosomático en un presente desolador. Sasha recuerda su boda con Enno, su convivencia errante en esta ciudad, la defunción de su bebé, y su triste trayectoria, ya en solitario, durante la cual llama a la puerta de comedores sociales regentados por monjas francesas para aplacar su consunción, y de amantes prospectivos que huirán de su estigma de indigencia. Su propensión vigente a reincidir en pautas de conducta masoquista se originó durante su matrimonio, cuando padeció persistentes humillaciones perpetradas por su cónyuge, que ella solía evacuar sólo mediante rebeliones imaginadas, nunca materializadas, como demuestra esta anécdota de servilismo femenino ante el regreso de Enno tras un injustificado período de abandono masculino del hogar familiar:

'I'm very thirsty', he says. 'Peel me an orange'. Now is the time to say 'Peel it yourself', now is the time to say 'Go to hell', now is the time to say 'I won't be treated like this'. But much too strong... I peel the orange, put it on a plate and give it to him. (Rhys 1939: 129)

Este fragmento delata que Sasha nunca osará cuestionar la obediencia a su esposo. En el presente narrativo de la obra, más de diez años después, Sasha está sola en la ciudad y ha envejecido. Estos factores intensifican su cuadro clínico bipolar, que intercala 
periodos depresivos de confinación en su cuarto, con otros de euforia con la búsqueda desesperada de diversión por las calles parisinas que, como la moda, la peluquería o los cosméticos, ofrecen una felicidad puntual y anestesian transitoriamente la punzante sensación de soledad y desasosiego:

When I go out into the Place de I'Odéon I am feeling happy, what with my new hair and my new hat and the good meal and the wine and the fine and the coffee and the smell of night in Paris. I'm not going to any beastly little bar tonight. No, tonight I'm going somewhere where there's music; somewhere where I can be with a lot of people; somewhere where there's dancing. (Rhys 1939: 71)

Entre los hombres que frecuenta, destaca el gigoló René que se acerca a ella creyendo que es una rica dama anglosajona. La heroína se carcajeará sardónicamente al detectar su modus operandi de derroche para cazar su "no" fortuna. Mientras que la marginalidad de la prostitución masculina en esta novela dialoga con la cosificación erótica de la mujer en Quartet, abrazando así ambas obras el convencional vínculo de París con el sexo, Rhys impulsará una permuta de género sobre los roles preestablecidos de cliente y meretriz al dotar a Sasha de superioridad decisoria y económica. En contrapartida, no romperá la praxis sexual de bestialidad del hombre y de masoquismo de la mujer. En su segunda cita, será ella quien gaste dinero y contrate los servicios de acompañamiento de René sin conllevar otros de tipología sexual-, que le aportarán una diversión momentánea. A su lado, imaginará o recordará un episodio vejatorio con un amante anterior que evidenciará su obsesión autodestructiva por el prototipo masculino sádico que este gigoló encarna:

I am in a little whitewashed room. The sun is hot outside. A man is standing with his back to me, whistling that tune and cleaning his shoes. I am wearing a black dress, very short, and heel-less slippers. My legs are bare. I am watching for the expression on the man's face when he turns round. Now he ill-treats me, now he betrays me. He often brings home other women and I have to wait on them, and I don't like that. But as long as he is alive and near me I am not unhappy. If he were to die I should kill myself. (Rhys 1939: 176)

Ya en la habitación del hotel parisino de su cliente, René no aceptará la afrenta femenina de no querer consumar la "transacción" amatoria. Sasha será entonces víctima de un encuentro sexual 
indeseado ${ }^{5}$, narrado con elipsis y entrecortada actividad cerebral de sumisión y parálisis, que sorprendentemente supondrá su retorno a la vida corporal, ya que recobrará sensaciones de dolor, escozor e invasión que permanecían atrofiadas o anestesiadas:

I lie very still, I don't move. Not open my eyes... 'Je te ferai mal', he says. 'It's your fault' [...] When I open my eyes I feel the tears trickling down [...] I feel his hard knee between my knees. My mouth hurts, my breasts hurt, because it hurts, when you have been dead, to come alive. 'Now everything's going to be all right', he says. 'T'as compris?' he says. Of course, the ritual answer is ' $\mathrm{Si}$, j'ai compris...' I lie there, thinking 'Yes, I understand'. (Rhys 1939: 182-183)

Paradójicamente, la heroína cumplirá su anhelo de revivir y despertar, que le condujo a regresar a París, aunque sea mediante otra herida psíquica y el traumatismo corporal de la violación. Ofrecerá dinero a René al temer una agresión aún más brutal. En cambio, al conseguir que éste abandone su habitación, comprobará que no le ha robado, por lo que dejará la puerta abierta y le llamará para que regrese junto a ella. Good Morning, Midnight concluirá con su protagonista desnuda, confinada en su prisión espacial y cerebral, así como alcoholizada, desorientada y anulada al invitar a su lecho a su vecino: un siniestro viajante con apariencia cadavérica que solía acosarla y aterrorizarla. La erótica del sufrimiento mental y fisiológico, congénita en la patología masoquista de las heroínas de Jean Rhys, cristalizará en dos incongruentes respuestas autodestructivas que detectan que su mayor pánico es la soledad en su cuarto-zulo parisino. Por un lado, la dependencia emocional del agresor después de una violación rematada o frustrada. Y por otro, el encuentro sexual-suicida con esta repulsiva sombra masculina que simbolizaría la muerte.

Jean Rhys perecerá literariamente por la falta de recepción lectora y crítica de estas novelas de entreguerras hasta resucitar tres décadas después gracias a Wide Sargasso Sea. En Quartet y Good Morning, Midnight, su prosa evasiva y oblicua, que convierte en virtud su reticencia a narrar historias cronológicas, parte de su autobiografía para trazar una cartografía inmovilista de la sensibilidad femenina y de su experiencia traumática en una "Ciudad de la Luz" en penumbra y sin claroscuros. Debajo de su capa estratosférica de burguesía acomodada, nácar turístico y brillantina cabaretera, en sus obras prevalecen las sombras de un "mundo de fieras", dominado no sólo por el sexismo, el racismo y el clasismo, sino también por la

\footnotetext{
${ }^{5}$ Al escribir esta obra, Rhys recordó el episodio doloroso de su pubertad: los abusos sexuales y sádicos perpetrados por Mr. Howard cuando ella sólo tenía 14 años (Linett 2005: 445-446).
} 
ausencia de humanidad y empatía que, en cambio, no desencadenará la insurrección iracunda de su "subsuelo" femenino. La mirada de doble insularidad de Rhys, antillana en la metrópoli y británica en el continente europeo, agravará su sentimiento de extranjería física y alteridad psíquica que incidirá en el realismo desgarrador y poco regenerativo de su creación literaria. Mediante sus heroínas vagabundas y cautivas, demostrará su conocimiento en primera persona del urbanismo, la fauna y el mobiliario del París de los años veinte y treinta con un claro objetivo desmitificador. El núcleo urbano no será inicialmente para Marya y Sasha un espacio inhibidor o represor, ya que explorarán rutas alternativas al trazado simétrico por vías serpenteantes, callejones irregulares y espacios abiertos. Sin embargo, sus "dueños masculinos" pondrán en peligro la habitabilidad de la capital francesa para este colectivo femenino, y acentuarán un rotundo binarismo de género que la novelista denunciará, aunque no lo combatirá narrativamente: la pasividad, la vulnerabilidad y la dependencia psicológica de mujeres explotadas sexual y emocionalmente por hombres despiadados que ostentarán la autoridad sobre ellas al forzar su confinación masoquista, y sobre la fachada externa de un París normativamente ordenado y geométrico.

\section{Bibliografía}

ABEL, Elizabeth (1979): "Women and Schizophrenia: the Fiction of Jean Rhys". Contemporary Literature, vol. 20, núm. 2, pp. 155-177.

ALVAREZ, Al (1971): The Savage God: Study of Suicide. London: Bloomsbury.

HENKE, Suzette A. (2000): Shattered Subjects: Trauma and Testimony in Women's Life-Writing. New York: St. Martin's Press.

HERMAN, Judith (1992): Trauma and Recovery: the Aftermath of Violence. From Domestic Abuse to Political Terror. New York: Basic Books.

HOWELLS, Coral Ann (1991): Jean Rhys. New York \& London: Harvester Wheatsheaf.

LE CORBUSIER (1929): The City of Tomorrow and its Planning. Traducción de Frederick Etchells. New York: Dover.

LINETT, Maren (2005): "New Words, New Everything: Fragmentation and Trauma in Jean Rhys". Twentieth Century Literature, vol. 51, núm. 4, pp. 437-466.

MILLETT, Kate (1969): Sexual Politics. Chicago: University of Illinois Press.

MORAN, Patricia (2007): Virginia Woolf, Jean Rhys, and The Aesthetics of Trauma. New York: Palgrave Macmillan.

MORRELL, A. C. (1979): "The World of Jean Rhys's Short Stories". World Literature Written in English, vol. 18, núm. 1, pp. 235-244.

NARDIN, Jane (2006): "'As Soon as I Sober up I Start Again': Alcohol and the Will in Jean Rhys' Pre-War Novels". Papers on Language and Literature, vol. 42, núm. 1, pp. 46-72.

POPEANGA CHELARU, Eugenia (2009): "Modelos urbanos: de la ciudad moderna a la ciudad posmoderna" [en línea]. Ángulo Recto. Revista de estudios de la ciudad como espacio plural, vol. 0. En: 
http://www.ucm.es/info/angulo/volumen/Volumen0/articulos01.htm [Consulta: 08/08/2013]

RHYS, Jean (1929): Quartet. New York \& London: Norton.

- (1939): Good Morning, Midnight. New York \& London: Norton.

SAVORY, Elaine (2009): The Cambridge Introduction to Jean Rhys. Cambridge: Cambridge University Press.

WALKER, Lenore (1984): The Battered Woman Syndrome. New York: Springer.

ZEIKOWITZ, Richard E. (2005): "Writing a Feminine Paris in Jean Rhys' Quartet". Journal of Modern Literature, vol. 28, núm. 2, pp. 1-17. 